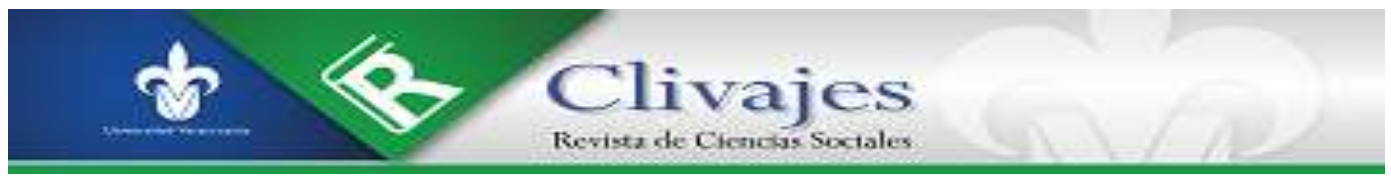

Itzel López Nájera

PUGNAS EN TORNO A LA GRATUIDAD:

LOS HUELGUISTAS DEL MOVIMIENTO ESTUDIANTIL 1999-2000 EN LA UNAM

Clivajes. Revista de Ciencias Sociales. Año VII, número 13, enero-junio 2020, pp. 98-117.

https://clivajes.uv.mx/index.php/Clivajes/editor/proofGalley/2650/4465

Instituto de Investigaciones Histórico-Sociales, Universidad Veracruzana

Clivajes. Revista de Ciencias Sociales/ISSN: 2395-9495/IIH-S, UV/Xalapa, Veracruz, México

Recibido: $27 / 11 / 2019$

Aceptado: 10/12/2019

Dictaminado: 09/05/2020 


\title{
PUGNAS EN TORNO A LA GRATUIDAD: LOS HUELGUISTAS DEL MOVIMIENTO ESTUDIANTIL 1999-2000 EN LA UNAM
}

\author{
Itzel López Nájera*
}

\begin{abstract}
Resumen
En 1999 y primeros meses del año 2000, un movimiento estudiantil sacudió a la Universidad Nacional Autónoma de México (UNAM): la huelga contra el aumento de cuotas que paralizó por casi diez meses las actividades de la Máxima Casa de Estudios del país. En este artículo se expone parte de la investigación de la autora sobre este conflicto que significó un espacio de fuerte controversia sobre algunas medidas educativas en dicha institución. El movimiento, que fue ampliando sus demandas conforme aumentaba la politización de los estudiantes, representa una coyuntura emblemática de cuestionamientos a las políticas "neoliberales".

El trabajo se centra en la gratuidad que, según el Consejo General de Huelga (CGH), quedaba vulnerada frente a la amenaza de "privatización", una de las medidas promovidas por instancias financieras internacionales, respaldadas por regímenes de verdad de algunos teóricos de la economía. Para ello, se retoman testimonios de personas que participaron en el movimiento y mantuvieron la reivindicación de las demandas hasta que la huelga se interrumpió con la intervención de la Policía Federal Preventiva (PFP) en la UNAM.
\end{abstract}

Palabras clave: Movimiento estudiantil, Neoliberalismo, Privatización, Gratuidad, Consejo General de Huelga

\section{INTRODUCCIÓN}

El año 2019 resulta emblemático para el movimiento estudiantil mexicano. Se cumplen 20 años de aquella huelga universitaria que estalló el 20 de abril de 1999 en las distintas escuelas y facultades de la UNAM, y concluyó con la violación a la autonomía universitaria por parte de la Policía Federal Preventiva (PFP). El rompimiento abrupto; el desgaste de más de nueve meses de cierre; la coyuntura electoral que se avecinaba; el ascenso de un partido de "izquierda" (Partido de la Revolución Democrática, PRD) al gobierno de la capital del país; el empecinamiento de las posiciones más participativas en el movimiento, así como las posturas de los medios de comunicación (incluso los más cercanos a la crítica) conformaron un escenario de confrontación constante, que perduró hasta años después de concluido el paro. A la fecha, las autoridades universitarias han reconocido, en diferentes espacios, lo poco que se han discutido los efectos de ese

\footnotetext{
* Profesora-investigadora, coordinadora de las Maestrías en Educación en la Universidad Iberoamericana Puebla, miembro del Consejo Mexicano de Investigación Educativa (COMIE), de la Red Mexicana de Estudios de los Movimientos Sociales y del Sistema Nacional de Investigadores, Nivel Candidata. Es doctora y maestra en Investigaciones Educativas (DIECINVESTAV, IPN) y licenciada en Sociología (FCPS, UNAM).
} 
movimiento para la universidad y para la política educativa de nivel superior en nuestro país.

A cincuenta años del movimiento de 1968, los ex miembros del Consejo General de Huelga vieron con beneplácito la reivindicación de la huelga del 99 en diversos carteles que desfilaron por las calles durante la marcha del 2 de octubre. Nuevas generaciones de activistas reconocen en este movimiento un legado que configura la protesta actual, así como un triunfo en la preservación del monto de las cuotas previas al intento de aumentarlas. No sólo en este sentido es productivo repensar aquella huelga; es necesario también ahondar en los vínculos entre movimientos sociales y la manera en que inciden en la configuración de políticas públicas; para el caso de este artículo, es posible analizar la forma en la que se significó la amenaza sobre la "gratuidad" a manera de cobro de cuotas, y cómo las distintas posturas al interior de la universidad se aprestaron a defender lo que consideraron un derecho irrenunciable.

Para los propósitos de este texto, la exposición se realiza de la siguiente manera: primero, se plantea el telón de fondo sobre el cual se sostuvo la relación antagónica entre huelguistas y autoridades educativas universitarias, es decir, la incorporación de lógicas economicistas de corte "neoliberal" en la formulación de medidas y la toma de decisiones universitarias; después se va anclando el argumento en torno a la amenaza que representaban estas medidas para la "gratuidad" de la educación superior, lo cual desemboca en una pugna por su significación y alcances; y, finalmente, se emplea el recurso del testimonio para ejemplificar la posición de sujeto huelguista en la defensa de lo que consideró su derecho a acceder al nivel educativo superior. ${ }^{1}$

RACIONALIDAD NEOLIBERAL: DESPLAZAMIENTO DE LÓGICAS DEL DISCURSO ECONÓMICO AL EDUCATIVO

Aunque el análisis del discurso neoliberal se ha anclado en distintos posibles objetos de investigación, aquí solo se retoma una parte de la discusión que en aquellos tiempos -los años en que se desarrolló el movimiento, para ser más precisos- resultó significativa para las condiciones de circulación de las lógicas que sustentaron este entramado. Aunque a estas alturas es posible hablar de una discusión post-neoliberal con el ascenso de los

\footnotetext{
${ }^{1}$ Para ello se cuenta hasta el momento con 15 entrevistas a profundidad, realizadas a participantes del movimiento estudiantil, con el siguiente perfil: activistas que vivieron la huelga en diversas escuelas; reivindicaron las demandas y participaron hasta el último momento (6 de febrero del año 2000) desde diversas posibilidades de participación; se asumieron como miembros de las "bases" y no como "dirigentes" de grupos o miembros de corrientes.
} 
gobiernos populistas latinoamericanos, la idea es situar al lector en los términos en los que se desarrolló la discusión en ese contexto específico, en el que sus lógicas se sedimentaron y diseminaron a lo largo del país.

¿Qué es posible entender cuando hablamos de "neoliberalismo"? Enuncio brevemente algunos de sus rasgos más representativos y la manera en que sus lógicas se desplazaron hacia la formulación de políticas educativas en la década de los noventa. En su ya clásico ensayo "De ambulancias, bomberos y policías: La política social del neoliberalismo”, Carlos María Vilas (1998), politólogo argentino, enuncia algunos de los rasgos más representativos de este modelo económico que reemplazó las políticas de tendencia universalista durante el periodo del Estado "benefactor":

De manera muy simplificada, éste (el modelo neoliberal) se caracteriza por: i) desregulación amplia de la economía; ii) apertura asimétrica; iii) desmantelamiento del sector público; iv) autonomía del sector financiero respecto de la producción y el comercio [...] en estas condiciones lo social es considerado ante todo una dimensión del gasto, no de la inversión; el concepto de desarrollo social se diluye y cede terreno al de compensación social [...] en consecuencia, la política social se contrae, y sus dos funciones tradicionales -acumulación y legitimación- experimentan severas adaptaciones (pp. 115-116).

De las características mencionadas por el autor, la que interesa remarcar aquí remite a la cuestión del "desmantelamiento público" como una de las condiciones de producción del movimiento estudiantil de 1999 en la UNAM, así como de la conformación de subjetividades críticas hacia las políticas de corte "neoliberal”.

Con la propagación del discurso de un supuesto agotamiento del modelo de Estado benefactor que defendía -al menos programáticamente- los derechos de carácter universal, se fue instaurando una lógica emergente que apeló a la "elección racional" aparejada con la liberalización de los mercados para optimizar el gasto público. Se propuso la contracción de la intervención estatal en la regulación de la economía, con el objetivo de desembarazarla de intereses políticos, personales e "ideologías" que impedían el libre desarrollo de las fuerzas productivas, apegándose a la doctrina de que:

La libre operación del mercado garantiza en el largo plazo la asignación racional de los recursos; los desequilibrios son producto de elementos ajenos a él. El principal de éstos es la intervención del Estado motivada por criterios políticos, ideológicos; en general no económicos. Solo se acepta la intervención estatal encaminada a restablecer el juego libre del mercado, pero aun así con recelo: éste tiene mecanismos autorreguladores que son suficientes para recuperar el equilibrio (Vilas, 1998, p. 111). 
La racionalidad sobre la cual se fue fincando el discurso neoliberal desde inicios de la década de los ochenta presenta fuertes rasgos deterministas que caracterizan a una entidad (el Estado) como un impedimento para la autorregulación de los mercados, su crecimiento y el derrame de sus beneficios a la población. Se plantea un mercado con agencia propia que se autorregula, dirige y "decide" el rumbo más idóneo de las orientaciones económicas y sociales. Su argumentación oculta las específicas relaciones de poder que lo sostienen y las decisiones particulares que le dieron sustento en su momento de irrupción como lógica emergente.

De la década de los ochenta a la actualidad, se ha venido sedimentando el discurso neoliberal en distintos órdenes de la vida pública, mostrando la fuerza de su naturalización a la hora de la toma de decisiones en los distintos espacios sociales. Los diferentes entramados que coadyuvan en su sostenimiento constituyen un tejido pretendidamente homogeneizante que produce efectos de verdad a todo el conjunto. La coherencia entre lo que se plantea para las políticas de salud, para la educación, para las políticas sobre el trabajo, etc., en buena medida enarboladas en documentos de "recomendaciones" de organismos como el Banco Mundial, le da sentido y le permite estructurar sus iniciativas en distintos planos de la vida social: "En la periferia, cuando una clase capitalista débil y subordinada y un Estado endeudado son incapaces de formular una política universitaria compatible con el nuevo paradigma económico, quien enfrenta esta tarea es una red de agencias internacionales encabezadas por el Banco Mundial” (Schugurensky, 2001, p. 14).

Dentro de esta red, el discurso educativo ocupa un sitio propio, con características específicas sobre la conducción de sus mecanismos. Interesa aquí remarcar uno de ellos, el de la "privatización":

Se fundamenta la privatización en la necesidad de aliviar la crisis fiscal, incrementar la eficacia de la oferta de servicios y evitar las irracionalidades a que induce su gratuidad, tanto a nivel macroeconómico como microeconómico. La privatización acarrea la introducción o aumento del arancelamiento de los servicios y la introducción de criterios de negocio y de ganancia comercial, con fuertes repercusiones en la calidad y extensión de la cobertura. El arancelamiento de los servicios es visto como un medio de relevar a los organismos prestatarios de al menos parte de su carga financiera y de asegurar que los servicios solo serán demandados por quienes efectivamente los necesitan, con lo cual se evita el derroche de recursos (Vilas, 1998, p. 119).

La racionalidad neoliberal, sedimentada y diseminada mediante un poderoso dispositivo económico e intelectual, produce efectos de verdad apelando a la racionalización del recurso escaso y la evitación del derroche, y, de este modo, un 
derecho que se concibe como "universal" se convierte en una irracionalidad costosa de sostener, para lo cual es necesario: 1) focalizar los recursos sólo sobre quien -se dice"realmente los necesita"; y, 2) apelando a la "corresponsabilidad", haciendo a los beneficiarios partícipes del gasto en ellos realizado, concibiéndolo como una inversión que a ellos retribuirá principalmente.

Todo servicio público se vio en la posibilidad de ser trastocado por las Políticas de Ajuste Estructural (PAE) que, mediante reformas, instauraron el orden emergente así argumentado, interpelando al sujeto a creer que es el orden más racional posible en la actualidad (frente a un Estado gigantesco, derrochador, que no ahorra ni planifica, y cuyos artífices - los políticos-son responsables de la crisis). Frente a este escenario dislocatorio, emerge el mito neoliberal que se propone reestructurar los elementos estallados y ofrecer un orden posible:

Con la aplicación de las políticas neoliberales, el Estado se aparta de su responsabilidad de administrar los recursos públicos ${ }^{2}$ y de la premisa liberal de luchar por la igualdad entre los ciudadanos, dejando en su lugar una fe ciega en el mercado y la esperanza de que el crecimiento económico genere, si acaso, un excedente suficiente para poder ayudar a los pobres y a los marginados (Schugurensky. 2001, p. 11).

El nuevo espacio de representación deposita la fe en un determinismo economicista que apela a una "mano invisible", despolitizando todo el proceso de toma de decisiones al interior de las instancias trasnacionales que orientan los discursos que nutrirán las políticas educativas en los países. El horizonte de plenitud aparece, así, como algo despersonalizado y, al mismo tiempo, exclusivamente racional. El Estado de bienestar, que se legitimó por décadas bajo el cobijo de la seguridad social, vira hacia un Estado neoliberal legitimado por el mercado (despersonalizado) y hacia el individuo (un sujeto “corresponsable”):

El Estado, a la vez que abandona el sistema de provisión social y reduce su papel en ámbitos como la asistencia sanitaria, la educación pública y los servicios sociales, que antes fueron tan esenciales para el liberalismo embridado, también deja segmentos cada vez mayores de población expuestos al empobrecimiento. El sistema de la seguridad social se ve reducido a su mínima expresión para ceder el paso a un sistema que hace hincapié en la responsabilidad personal. La incapacidad personal se atribuye por regla general a fracasos personales, y en la mayoría de los casos, se culpabiliza a las víctimas de su situación (Harvey, 2007, pp. 85-86).

\footnotetext{
${ }^{2}$ Líneas abajo, en la parte de “cierre”, se hace matices importantes a afirmaciones tajantes de este tipo.
} 
La amenaza de no sujetarse a estas recomendaciones iría en detrimento del acrecentamiento y procuración del propio capital cultural, de forma tal que no hacer el esfuerzo en la inversión de su propia educación, resultará autodestructivo y condenable:

El éxito o el fracaso personal son interpretados en términos de virtudes empresariales o de fallos personales (como puede ser no invertir de manera suficiente en el propio capital humano a través de la educación) en lugar de ser atribuidos a ningún tipo de cualidad sistémica (como las exclusiones de clase normalmente atribuidas al capitalismo) (Harvey, 2007, p. 75).

En la década de los noventa se diseminó, como objeto de estudio, el vínculo "neoliberalismo" y educación, es decir, la manera en que el entramado conceptual y las lógicas emergentes del capital modularon otros ámbitos de la vida pública, entre ellos, la forma en la que comenzó a conceptualizarse a las instituciones de nivel superior. Laval (2004) señala las diversas formas de la mercantilización que adoptó este espacio en diversas partes del mundo, que van desde las empresas que quieren penetrar en el terreno escolar; la comercialización del espacio escolar; la concepción de escuelas como empresas productoras de mercancías específicas, hasta la mercantilización de los productos educativos. En Gran Bretaña, uno de los laboratorios de este modelo:

Thatcher redujo durante los años ochenta el presupuesto destinado para la educación, volvió a enfocar el sistema educativo hacia las necesidades de la industria, promovió fuertes apoyos del gobierno para las universidades privadas e intentó transformar las instituciones de educación superior en empresas privadas con fines lucrativos [...] el resultado fue un aumento considerable de la dependencia fundamental de fuentes alternativas de recursos (como las donaciones para la investigación, los contratos y el pago de matrículas) (Schugurensky, 2001, p. 18).

Las aportaciones familiares corresponden a la racionalidad instaurada, en el sentido de que la inversión en uno mismo repercutirá en la acumulación de capital cultural y, por ende, en mayores posibilidades de obtener un trabajo mejor remunerado en el futuro. Laval (2004) lo expone así, parafraseando a David Friedman (hijo de Milton Friedman):

La educación es un bien de capitalización privada que aporta beneficios fundamentalmente personales, pero que también supone sacrificios por parte de las familias. Incluso los más pobres, dice este autor, serían capaces de financiar los estudios de sus hijos si aceptasen realizar los esfuerzos necesarios. La ausencia de financiación pública enfrentará a las familias ante su responsabilidad y la falta de educación de los hijos solo será entonces debida a la 
despreocupación de padres que eligen un bienestar inmediato en detrimento de la felicidad futura de su progenie (p. 144).

La privatización de la educación en el modelo neoliberal implica la apertura de cada vez más Instituciones de Educación Superior (IES) privadas, ${ }^{3}$ pero sobre todo se juega en torno a la privatización de la educación de carácter público y la manera en que ésta se va resignificando en sus funciones, pasando de ser un derecho que provee el Estado $^{4}$ a ser una inversión auspiciada por las aportaciones de las familias: "La ideología liberal acompaña, refuerza y legitima las diversas formas de desregulación, cuya característica general consiste en habilitar un lugar creciente en el espacio escolar para los intereses particulares y las financiaciones privadas, ya sean cosa de las empresas o de los individuos" (Laval; 2004: 159). La diversificación de las fuentes de financiamiento recae en los padres de familia o directamente en los estudiantes de las IES del sector público, quienes ingresan al campo laboral para poder continuar con sus estudios. Nuevamente, esta corresponsabilidad en la inversión, se argumenta con la intención de descargar al Estado en un área que le resulta costosa, arguyendo que si alguien llega a la universidad pública, es porque posee los medios necesarios para sostenerse en ese sitio.

\section{LA PUGNA POR LA GRATUIDAD}

El 15 de marzo de 1999, en la Universidad Nacional Autónoma de México, el Consejo Universitario (CU) aprobó, en el Instituto de Cardiología, el nuevo Reglamento General de Pagos (RGP), que sustituía al de 1966 y actualizaba las cuotas establecidas desde 1948. Previo a esto, la comunidad y los grupos organizados en su interior habían iniciado ya una amplia labor de agitación en torno a la inminencia de la aprobación de esos montos nuevos. En dicho documento se estableció que las cuotas semestrales para el nivel Bachillerato serían de 15 días de salario mínimo, mientras que las cuotas de Licenciatura corresponderían a 20 días. $^{5}$

No era la primera vez que se pretendía modificar el monto de las cuotas. En 1986, el movimiento del Consejo Estudiantil Universitario (CEU) había detenido ya un intento previo en ese sentido. Trece años después, el RGP volvía a escena. En el Artículo $7^{\circ}$ del mencionado documento, se planteó que: "los alumnos cuyo nivel familiar mensual

\footnotetext{
${ }^{3}$ Fenómeno que ha proliferado en forma de las despectivamente llamadas "escuelas patito".

${ }^{4}$ Aunque no por ello sea del todo "gratuita".

${ }^{5}$ En el estatuto se plasmó que las cuotas, que hasta el momento se habían mantenido en 20 centavos, se incrementarían a $\$ 1360$ pesos para estudiantes de bachillerato, y \$2 040 para los de licenciatura.
} 
sea igual o menor a 4 salarios mínimos tendrán derecho a la exención de la cuota semestral. Para obtener la exención, bastará con que los alumnos que la requieran formulen, bajo protesta de decir verdad, la solicitud correspondiente". Algunas preguntas rondaron el ambiente en ese momento. ¿Era posible que, al margen de un monto específico - bajo o elevado-, a lo que tendía la medida era a instaurar una lógica de consumo de la educación superior? ¿Es posible que la medida tendiera a formar sujetos acostumbrados a pagar por lo que hasta entonces había sido considerado como un derecho "gratuito"? En el documento Universidad responsable, sociedad solidaria, se plantea que:

Los montos actuales de las colegiaturas, de 15 centavos en bachillerato y 20 en licenciatura, corresponden a los \$150 y \$200 que la Universidad ha cobrado por colegiaturas desde 1948 . Sin embargo, los $\$ 200$ que se pagaban en la década de los cincuenta tenían un poder adquisitivo equivalente a 60 días de salario mínimo actual. La reforma al Reglamento General de Pagos apenas restituye el valor que tenían las cuotas de inscripción y colegiatura cuando fueron modificadas por última vez (Propuesta de modificación al RGP, 11 de febrero de 1999).

Esta lectura descontextualizada que presentó el documento para justificar el aumento de las cuotas, no reparó en la significación que se sedimentó durante los cincuenta años transcurridos entre 1948 y 1999, en los que no se modificaron los montos y la manera en que se había ya configurado un tipo de beneficiario de la educación de ese nivel. Tanto las políticas emanadas del modelo "de bienestar", como la significación histórica de los derechos conquistados y sedimentados por el régimen posrevolucionario, contribuyeron a generar un imaginario de acceso "universal" al nivel superior entre los beneficiarios de la educación pública.

En concreto, se pretendió sustituir a un Estado que se produjo en sus lógicas de legitimación, tratando de asegurar a la población en términos de derechos universales y gratuitos (en realidad, pagados mediante impuestos), por un nuevo horizonte de inscripción. En ese sentido, esta iniciativa y este documento representaron, para muchos de los estudiantes, una de las formas en las que se pretendía instaurar la política neoliberal en la educación superior.

La "gratuidad" de la educación superior fue uno de los grandes debates que rodearon el movimiento estudiantil de 1999, sobre todo porque se cuestionó si las cuotas estaban permitidas o prohibidas, en qué sentido, o si el financiamiento del nivel superior era responsabilidad única del Estado en la Máxima Casa de Estudios. En función del planteamiento legal, se argumentó la pertinencia/impertinencia de la huelga y su sostén 
jurídico. La ambigüedad de los artículos permitió que se generara la polémica en cuanto a los alcances y limitaciones de las funciones del Estado en términos de gratuidad. Aquí sólo presento un breve ejercicio de rastreo que ayudará a entender en qué términos se anclaron los participantes del movimiento y su discusión en torno a este punto. El ejercicio se realiza sin pretensiones de relanzar un debate legal al respecto; antes bien, lo que interesa remarcar aquí es la función pragmática de la "gratuidad" en el imaginario de la población que se beneficia de este bien público, ${ }^{6}$ la cual le permite asumir que, efectivamente, la educación impartida en la UNAM es gratuita, al margen de estipulaciones y precisiones legales que así lo argumentan.

Diario Oficial, 13 de diciembre de 1934, Lázaro Cárdenas, decreto que reforma el artículo $3^{\circ}$. "Solo el Estado -Federación, estados, municipios-impartirá educación primaria, secundaria y normal [...] La educación primaria será obligatoria y el Estado la impartirá gratuitamente.”

No aparece la educación superior universitaria al referir la gratuidad; ésta sólo incluye al nivel básico de primaria.

Diario Oficial, 30 de diciembre de 1946, Miguel Alemán Valdés, decreto que reforma el artículo $3^{\circ}$. "VI La educación primaria será obligatoria. VII Toda la educación que el Estado imparta será gratuita."

No especifica más sobre los niveles considerados en dicha gratuidad, pero da pie a una configuración imaginaria donde el Estado se presenta, en los hechos, como el garante de toda la educación que imparte.

Diario Oficial, 9 de junio de 1980, José López Portillo, decreto que reforma el artículo $3^{\circ}$ consistente en la adición de la fracción VIII: "Las universidades y las demás instituciones de educación superior a las que la Ley otorgue autonomía, tendrán la facultad y la responsabilidad de gobernarse a sí mismas; realizarán sus fines de educar, investigar y difundir la cultura de acuerdo con los principios de este artículo, respetando la libertad de cátedra e investigación y de libre examen y discusión de las ideas; determinarán sus planes y programas; fijarán los términos de ingreso, promoción y permanencia de su personal académico; y administrarán su patrimonio.”

\footnotetext{
${ }^{6}$ Anclado, como se dijo previamente, en las políticas producidas por las instituciones posrevolucionarias que fueron produciendo beneficiarios de servicios cada vez más demandantes.
} 
Se plantea que la autonomía permite la administración del patrimonio de las universidades, aunque no especifica la procedencia de los fondos.

Diario oficial, 1993, Carlos Salinas de Gortari: "Todo individuo tiene derecho a recibir educación. El Estado - la Federación, Estados y Municipios-impartirá educación preescolar, primaria y secundaria. La educación primaria y la secundaria son obligatorias [...] IV Toda la educación que el Estado imparta será gratuita; V Además de impartir la educación preescolar primaria y secundaria, señaladas en el primer párrafo, el Estado promoverá y atenderá todos los tipos y modalidades educativos incluyendo la educación superior- necesarios para el desarrollo de la Nación, apoyará la investigación científica y tecnológica, y alentará el fortalecimiento y difusión de nuestra cultura; VII las universidades y las demás Instituciones de Educación Superior a las que la ley otorgue autonomía, tendrán la facultad y la responsabilidad de gobernarse a sí mismas; realizarán sus fines de educar, investigar y difundir la cultura de acuerdo con los principios de este artículo, respetando la libertad de cátedra e investigación y de libre examen y discusión de las ideas; determinarán sus planes y programas; fijarán los términos de ingreso, promoción y permanencia de su personal académico; y administrarán su patrimonio."

El fragmento corresponde a la reforma impulsada durante el sexenio presidencial de Salinas de Gortari, y señala que la educación superior será atendida y promovida por el Estado. Se enuncia una diferencia respecto de la educación obligatoria (de nivel básico), pero no termina de aclararse si en esta distinción la educación superior no es "gratuita".

Ley general de Educación, 1993, Carlos Salinas de Gortari: "ARTíCULO 9o.- Además de impartir la educación preescolar, la primaria y la secundaria, el Estado promoverá y atenderá -directamente, mediante sus organismos descentralizados, a través de apoyos financieros, o bien, por cualquier otro medio- todos los tipos y modalidades educativos, incluida la educación superior, necesarios para el desarrollo de la Nación, apoyará la investigación científica y tecnológica, y alentará el fortalecimiento y la difusión de la cultura nacional y universal [...] En el cumplimiento de lo dispuesto en los artículos anteriores de esta sección, el Ejecutivo Federal y el gobierno de cada entidad federativa tomarán en cuenta el carácter prioritario de la educación pública para los fines del desarrollo nacional. En todo tiempo procurarán fortalecer las fuentes de financiamiento a la tarea educativa y destinar recursos presupuestarios crecientes, en términos reales, para la educación pública.”

En la Ley de 1993, específicamente dedicada a cuestiones de orden educativo, se remarca el papel del Estado rector y promotor de la educación pública, mediante apoyos 
financieros. El fortalecimiento de las "fuentes de financiamiento" da pie a cierta ambigüedad sobre la posible procedencia de los recursos. Si bien la última modificación al artículo $3^{\circ}$, que produjo efectos sobre la política educativa de los años noventa, se firmó en 1993, todos los textos anteriormente expuestos se encontraban íntimamente relacionados al siguiente ordenamiento:

Ley para la Coordinación de la Educación Superior, publicada en el Diario Oficial de la Federación el 29 de diciembre de 1978 [texto vigente en el momento de la huelga]: Artículo 11. "A fin de desarrollar la educación superior en atención a las necesidades nacionales, regionales y estatales y a las necesidades institucionales de docencia, investigación y difusión de la cultura, el Estado proveerá a la coordinación de este tipo de educación en toda la República, mediante el fomento de la interacción armónica y solidaria entre las instituciones de educación superior y a través de la asignación de recursos públicos disponibles destinados a dicho servicio, conforme a las prioridades, objetivos y lineamientos previstos por esta Ley."

Artículo 21. "La Federación, dentro de sus posibilidades presupuestales y en vista de las necesidades de docencia, investigación y difusión de la cultura de las instituciones públicas de educación superior, les asignará recursos conforme a esta Ley para el cumplimiento de sus fines. Además, las instituciones podrán llevar a cabo programas para incrementar sus recursos propios y ampliar sus fuentes de financiamiento.”

La ambigüedad de las leyes en materia de "gratuidad", es decir, el que no se especifique en todo momento que toda la educación que imparta el Estado será gratuita; el hecho de que dicha gratuidad no estuviera señalada, tal cual, con respecto al nivel superior, como sí lo estaba con respecto al básico; el hecho de que se asumiera la responsabilidad del Estado con la educación superior, de “promoverla y atenderla”, así como de destinarle recursos presupuestarios crecientes; el que además se argumentara la posibilidad de diversificar sus fuentes de financiamiento, sin clarificar que las IES fuesen auspiciadas por cuotas u otros mecanismos, dio pie a una lucha por su significación en un contexto en el que muchos veían amenazado un derecho irrenunciable.

Tal espacio de ambigüedad en las leyes nacionales se conjuntó con el criterio imperante de la costumbre, es decir, con el aspecto consuetudinario de la gratuidad al que los huelguistas recurrieron para fortalecer su argumentación respecto a la necesidad y justeza del paro: si los montos de las cuotas no se habían modificado en 50 años, epor qué habrían de reconocerse en un contexto amenazante que auguraba la privatización de 
los servicios públicos? ¿Por qué desambiguar la ley precisamente en ese momento? ${ }^{7}$ En las subjetividades huelguistas estaba muy arraigada la idea de la educación gratuita (incluyendo la de nivel superior), entendida como un derecho, debido a la sedimentación que durante cinco décadas operó alrededor de ese imaginario.

¿Cuál fue la demanda del movimiento que articuló las distintas posiciones al interior de la UNAM? De un amplio entramado de corrientes moduladas por distintos juegos de lenguaje, desde maoístas, guevaristas, stalinistas, leninistas, zapatistas, anarquistas, pasando por los entramados partidistas (específicamente, los adscritos al PRD), hasta las posturas menos informadas o novatas, que nunca habían participado en discusiones políticas, el asunto de las cuotas y la gratuidad de la educación condensaron, de inicio, la voluntad de participar en torno al paro universitario. Varios de esos grupos provenían de procesos previos en los cuales no habían llegado a buen término o guardaban posturas irreconciliables, que sólo al calor de la aprobación del nuevo RGP pudieron quedar en segundo plano. En ese momento, lo importante era no quedar fuera de la coyuntura que se aproximaba.

\section{GRATUIDAD COMO DERECHO A DEFENDER}

Es posible caracterizar la "gratuidad" como un punto nodal (el más representativo del movimiento), en donde se condensaron las motivaciones que orillaron a los estudiantes a impulsar e incorporarse a la huelga. En las siguientes líneas, doy cuenta de la forma en la que algunos de los entrevistados, participantes del movimiento, significaron su contribución a la huelga, como parte de su defensa de la educación pública y gratuita, con base en la idea de que constituye un derecho a preservar y defender. Así recuerda un estudiante de la Escuela Nacional de Trabajo Social la manera en que se enganchó con la demanda de gratuidad:

E1: Fue como: "oye compañero, quiero hablar contigo, mira te quiero explicar”, ¿no?, entonces, creo que en ese momento pues me paré, lo escuché, yo decentemente me paré, pero al principio no lo escuchaba, o sea, lo oía, pero no lo escuchaba. Pero llegó un momento en que me dijo una frase que todavía la sigo teniendo en mi mente que fue: “qué vas a hacer si hacen la privatización del sistema educativo en la universidad y tus hijos, o tus sobrinos, o tus primos, no van a acceder porque solamente la gente que tenga dinero es la que va a tener posibilidad de entrar en la escuela?" Entonces eso se me quedó muy grabado porque mi familia es de clase

\footnotetext{
${ }^{7}$ Con esto me refiero no a la modificación del artículo $3^{\circ}$ Constitucional que, como vimos, tuvo su reforma anterior inmediata en 1993, sino al esclarecimiento que, en ese momento, el debate intentó alentar en las voces de los eméritos de la Facultad de Derecho y de otras figuras opositoras al paro.
} 
media baja. Yo soy el tercero en mi casa que iba a la universidad, de muchos hermanos, pero tengo muchos sobrinos y primos; y yo dije: “¡uy, caray!, pues detrás de mí todavía vienen muchos y tienen una posibilidad de tener una mejor calidad de vida con la educación”. Entonces eso me impactó, fue lo que hizo como que empecé a escuchar (Estudiante de Trabajo Social).

La carga significante que, en ese momento, tomó la posibilidad de no poder continuar con los estudios superiores movilizó a los estudiantes universitarios, quienes veían en las cuotas una amenaza a su proyecto de vida y de las generaciones venideras (específicamente, en la figura de sus hermanos menores). La identificación con la demanda, en el caso de este entrevistado, se enganchó, no con el discurso político que previamente le ofrecía el activista que intentaba convencerlo de su postura, ni con su argumentación sobre el "neoliberalismo" y los organismos internacionales, sino con la manera en que él y su familia se verían perjudicados con tal medida, es decir, con una interpelación afectiva que tocaba al proyecto de la familia, a su descendencia y su posibilidad de acceder a un título universitario.

Algo similar ocurre con otros entrevistados que, de pronto, se vieron envueltos en una exigencia económica educativa. A una estudiante de la Facultad de Ciencias Políticas y Sociales:

E2: Mis papás me decían: "es con lo que te vas a quedar, yo me voy a morir, y si te heredo dinero se te va a acabar, pero la educación en ti queda. Y el luchar con las bases de una buena educación siempre las vas a tener". Sí, me decía mi papá que uno de los mejores valores más importantes es tener educación. Y este neoliberalismo atenta con la educación, pues es por eso que se hace como tan importante luchar porque siga siendo gratuita (Estudiante de Sociología).

La forma en la que las cuotas se aprobaron, en una sesión fuera de los recintos acostumbrados para ese ejercicio, alejados de la comunidad universitaria que cuestionaba dicha medida, aunado a la escasa argumentación sobre la necesidad de elevarlas y el trabajo de diversos grupos políticos que pugnaron por detener la votación, reforzaron la sospecha de la necesidad de esta medida:

E2: Y empecé a escuchar precisamente este discurso de que eran recomendaciones del Fondo Monetario Internacional. Y bueno, yo dije: “¿qué tan cierto es?”, ¿no? Poco a poco comencé a leer básicamente de periódicos, ¿no?, y básicamente de La jornada, donde decían: "es que el alza de cuotas representa el 3\% del presupuesto de la UNAM", y tú te empezabas a preguntar: "bueno, si sólo es el 3\%, entonces, ¿en qué le va a servir a la UNAM?, si es el 3\%, ¿para qué lo cobran?”, ¿no?, y entonces ya empezabas como a indagar y a ver. Y sí encontrabas una especie de rechazo de las autoridades a querer explicarte, ¿no? De hecho, recuerdo que cuando aprobaron se fueron a cardiología a una sede alterna y pues ahí vamos los estudiantes como 
locos, ¿no?, persiguiéndolos [...] Este asunto de ver a la educación como un servicio, como que paga por él, porque si no, no lo aprecias, este discurso, lo empezaban a decir mucho, y empiezas a leer el artículo tercero de la Constitución Mexicana que decía que la educación debe ser pública y gratuita, y empiezas a hacer cuentas y a ver: pues si mis padres me tienen a mí, y a mi hermano y al otro ya no les va a alcanzar para que los tres estemos en la universidad, y si no representa tanto para la universidad, ¿qué caso tiene pagarlo, no? (Estudiante de Sociología).

La toma de posición frente a algunos de los significantes que configuran el discurso neoliberal (es decir, la intervención de organismos internacionales, el exhorto a la inversión en el propio capital cultural, el cuestionamiento a la gratuidad, el repliegue del Estado en algunas responsabilidades, la posibilidad de una privatización paulatina, la dificultad de seguir estudiando en un futuro o la amenaza a la existencia de este derecho) fue estructurada a partir de discursos antagónicos que dejaron huellas en el sujeto y en su forma de estar en el mundo. Se observa lo anterior, por ejemplo, cuando se cuestiona a los participantes sobre la herencia de la huelga:

E2: Pues qué pregunta tan difícil, me marcó, para siempre, para toda mi vida y siempre, siempre. Fue un proceso de conciencia porque es como darte cuenta que el poder no cede tan fácil, ¿no?, y que en ese no poder derrotarlo, vienen como frustraciones, de que: ¿para qué, de qué sirve, si al final ellos tienen los medios, los recursos, el dinero? Este neoliberalismo que sólo hace más ricos a los ricos, ¿no?, desventajoso, te hace ver la cruda realidad, te hace sentir más. A mí la huelga me dejó como [...] como más sensible, en donde te duele más la pobreza, te duelen más las injusticias (Estudiante de Sociología).

Una de las dimensiones que más se remarca en las entrevistas, es la concepción de la educación pública y "gratuita" como un derecho, frente al entramado neoliberal desde donde se le significa como una mercancía valuada en función de la escasez y la dificultad de su sostén. La confrontación que implicó el cambio epocal, es decir, la transición de un esquema estatal "benefactor" a uno refuncionalizado que reivindicaba el libre mercado, representó el arribo de un nuevo mito que pretendía ofrecer mayor eficiencia en la administración, y terminó sedimentándose y diseminando sus lógicas hacia otros ámbitos. En palabras de quien fuera, en ese momento, participante en el CCH-Azcapotzalco:

E3: Era también como esta parte de ipor qué tenemos que pagar por algo que ya estamos pagando, no? Toda esta parte de los impuestos, pues se plantea que es para eso, ¿no? Para que pueda haber educación, pueda haber salud, pueda haber programas sociales y ¿por qué teníamos que volver a pagar? [...] No es que no se pudieran pagar las cuotas. Había compañeros que venían de condiciones como muy precarias de vida, pero el punto no era si tú podías pagarlas o no, sino si la educación era un privilegio o un derecho, si era un privilegio lo puedes tasar y quien lo pueda pagar lo adquiere, ¿no? Si es un derecho, no importa cuáles son tus condiciones, 
tienes derecho a serlo; no importa si vienes de una familia profesionista que puede pagar cierto nivel de cuotas o si eres hijo de campesinos y tienes posibilidades o no, justamente se trata de considerar la educación un privilegio o un derecho, ¿no? Y nosotros insistíamos en que era un derecho y que no podía empezar a ser considerado un privilegio porque eso iba a degenerar en una dinámica mucho más elitista [...] ingresar a la universidad no es elitista en sí mismo, pero sí está muy acotado (Estudiante del CCH-Azcapotzalco).

Si bien el entrevistado del CCH-Azcapotzalco menciona las posibilidades de algunos perfiles estudiantiles y familiares de pagar los montos de las cuotas, otro de los entrevistados - estudiante de la Facultad de Filosofía y Letras- ancla su posibilidad de continuar estudiando en función de dichos cobros de la siguiente manera:

E4: Me hubiera costado mucho y a lo mejor sí hubiera tenido que dejar de estudiar, lo más seguro es que hubiera dejado estudiar, a pesar de que había unas cláusulas ahí en el reglamento general de pagos, de que se iba a hacer un estudio socioeconómico para que los que no tuvieran la capacidad de pagar esas cuotas pagaran otra cosa, porque sí se iba a pagar otra cosa, algo más simbólico, o fueran exentados de esto. A mí ese discurso no me convencía porque los mismos responsables de mantener el sistema corrupto universitario, eran los que te vendían la promesa de que no te iba a pasar a ti, o que tú ibas a estar exento de esto. Igual, a todos nos aventaron la zanahoria de que ya no iba a aplicar para nosotros porque no podría ser retroactivo, ${ }^{8}$ o sea, es que es lo mismo porque, o sea, yo hubiera exentado, por una o por otra razón, por la situación socioeconómica, o por esta situación de no retroactividad, pero se me hacía una chingadera porque tomamos conciencia de que la universidad es una institución pública y que el país tiene la riqueza necesaria como para garantizarla, entonces ¿por qué no hacerlo? y no lo quería hacer, precisamente porque iba en vías de la privatización. Entonces nada garantizaba que esa cláusula en un futuro se eliminara, nada garantizaba que esos cobros en un futuro se fueran más a la alza, dependiendo de la oferta y la demanda. Entonces sí, para mí hubiera sido pues determinante, ya no poder estudiar.

Es posible detectar las huellas del entramado de significación "neoliberal" en el discurso de los propios huelguistas, considerado como una vulneración de su derecho al acceso a la educación superior y una situación a la que debían enfrentarse en aras de preservar esa posibilidad. En ese sentido, hubo una interpelación negativa respecto de las recomendaciones de organismos internacionales (traducidos al ámbito nacional, en este caso, por las autoridades universitarias) y con respecto a la propuesta específica del Reglamento General de Pagos. Esta significación se reforzó entre los sujetos con perfil socioeconómico bajo, quienes vieron en la "gratuidad" su única posibilidad de acceso a la educación superior.

${ }^{8}$ Aquí cabe especificar que, en un inicio, el reglamento contempló el pago de cuotas para todos con posibles exenciones, y en una segunda versión se hicieron voluntarias para todos. 


\section{A MANERA DE CIERRE}

Con la exacerbación de las lógicas del Estado mercantilizado, operó un desplazamiento del discurso economicista, productivista y ultrarracionalista hacia diversos ámbitos de la vida social. En el educativo, ha tenido especial repercusión en torno al nivel superior, el cual se ha visto reconceptualizado y vinculado en función de los requerimientos de órdenes no necesariamente académicos. En aras de una política focalizada y corresponsable, se interpeló a los sujetos a ser copartícipes del financiamiento de su formación, situación que produjo una reacción opositora en un amplio sector del estudiantado universitario, en 1999: la medida del incremento a las cuotas representó la imposibilidad de seguir estudiando o de que las futuras generaciones pudieran hacerlo, además de significar la pérdida de un derecho social otrora sostenido.

El incremento en las cuotas dio pie a la conformación de una relación antagónica entre estudiantes y autoridades universitarias; ${ }^{9}$ estas últimas, en calidad de representantes de las medidas que atentaban contra la "gratuidad". Esta mutua negación derivó en el estallamiento de la huelga, la madrugada del 20 de abril. A partir de ese momento, se fue conformando un tenso clima de confrontación/diálogo constante entre ambas partes, que operó en las subjetividades huelguistas a largo plazo, lo cual se observa en las huellas que ha dejado el movimiento y la forma en la que éste es reivindicado por muchos de ellos, incluso a veinte años de distancia.

Para concluir, cabe hacer algunas anotaciones en torno a lo que se ha expuesto a lo largo del documento:

1) En todo momento he venido entrecomillando el término "neoliberalismo" en aras de alertar al lector. Con base en la perspectiva teórica que cobija este documento (el análisis político de discurso), es necesario dejar claro que no asumo ningún tipo de dicotomía esencialista entre Estado benefactor y Estado neoliberal, cual si uno de ellos fuese bueno y el otro malo, o cual si fuese posible distinguirlos de tajo en dos polos discursivos opuestos. La premisa es que hay traslapes entre ambos, contaminación entre modelos, presencia de uno en el otro, y que es necesario historizarlos en sus más contextuales operaciones, para dar cuenta de esta dimensión matizada. En ese sentido, en ningún momento se quiere asegurar que, en tiempos del llamado "Estado benefactor", no operaran lógicas productivistas al interior del planteamiento de ciertas políticas, así como tampoco se propone que, en la década de los 80 , haya habido un corte tajante que reinventara el Estado y lo refundara hacia el mercado por completo. Huellas de la política

\footnotetext{
${ }^{9}$ Aunque no exclusivamente contra ellas.
} 
educativa del llamado Estado de bienestar permanecen a la fecha, y la existencia de la universidad pública lo comprueba; sin embargo, los matices que reconfiguran sus entramados discursivos presentan emergencias que reconforman su identidad y le dan peculiaridad al proceso actual. En ese sentido, resulta más productivo para el análisis dar cuenta de las tensiones entre las continuidades y discontinuidades entre ambos modelos, que asegurar que uno concluyó y otro emergió con una propuesta totalmente nueva. En suma, nunca nada es totalmente "nuevo" (como a veces se afirma en juicios de sentido común), pero sí es susceptible de ser genealogizado en aras de mostrar la peculiaridad de su contexto específico.

2) "Gratuidad" es otro de los términos que he venido señalando entre comillas en este texto por una razón. De inicio, porque la educación no es, strictu sensu, un bien obsequiado, puesto que se financia con los impuestos de todos los mexicanos; pero más allá de esta precisión, en este artículo no se discute qué significa en términos legales la gratuidad de la educación superior ni cómo se operativiza de manera lineal eso que se reconoce como un "derecho" en la Constitución, sino cómo ésta fue significada por los participantes de la huelga, al grado de convertirse en algo defendible en una lucha que duró más allá de nueves meses. En ese sentido, la "gratuidad" significó ante todo un derecho sedimentado en la costumbre (aun cuando existía un reglamento que estipulaba el cobro de cuotas), que para muchos de los movilizados representó la única oportunidad de acceder a este nivel educativo. La actualización en los montos se simbolizó como una amenaza de despojo a ser neutralizada mediante la organización y la toma de las instalaciones universitarias. Al no estar especificada su definición en la Carta Magna, el concepto da pie a una ambigüedad productiva que le coloca en el sitio de la pugna política, o para decirlo en otros términos, hay una dimensión política en la ambigüedad de la "gratuidad" en torno a la cual se centró la discusión. Es importante señalar que si bien el motor de la movilización fue el rechazo al RGP, durante el proceso de huelga, se sumaron cada vez más demandas que pusieron en serio cuestionamiento la estructura de poder en la universidad y complicaron cada vez más la resolución del conflicto.

3) Otro punto a subrayar es el papel político que cumple la "amenaza", es decir, la experiencia de la pérdida que puede llegar a representar una medida/una reforma/una política para sus receptores. En esa recepción, los afectos operan como mecanismos de preservación que movilizaron, en este caso a los estudiantes, en aras de mantener un derecho para sí mismos y para las futuras generaciones. En ese sentido, la racionalidad del huelguista (que operaba mediante constantes discusiones y balances sobre las acciones a tomar para emplazar a la rectoría al diálogo y autoformarse, en círculos de estudio 
sobre temas diversos, para mejorar su argumentación frente al público, y participar en las recurrentes discusiones de las asambleas locales y generales) se complementó con la afianzada convicción de estar defendiendo una causa justa, que repercutiría en la propia familia y en las próximas generaciones.

Finalmente, cabe remarcar la productividad de esta lectura que, frente a la racionalidad instrumental, enfatiza la mirada afectiva que implica a los sujetos en los movimientos sociales, así como la manera en que estos producen efectos en la configuración de políticas educativas a mediano y largo plazo. Las decisiones no se toman, necesariamente, en términos de elección de los mejores medios para los fines deseados, sino que trascienden esa lógica y se instauran en la dimensión emotiva que mueve, en este caso a los estudiantes, a organizar una huelga que derivó en un proceso de largo y arduo trabajo, confrontación y formación.

\section{REFERENCIAS}

GOBIERnO DE MÉXICO (2019). Reformas constitucionales al artículo 3º. En Reformas constitucionales por artículo. México: H. Congreso de la Unión. Recuperado de: https: / / bit.ly/2DJ41qE.

. (1934, 1946, 1980, 1993). Diario Oficial de la Federación. México: SEGOB. Recuperado de: https://www.dof.gob.mx/.

. Ley General de Educación. Diario Oficial de la Federación, 13 de julio de 1993. México: SEGOB.

. Ley para la Coordinación de la Educación Superior. Diario Oficial de la Federación, 29 de diciembre de 1978. México: SEGOB.

Harvey, D. (2007). El Estado neoliberal. En Breve historia del neoliberalismo. Madrid: Akal.

LAVAL, C. (2004) La gran ola neoliberal. En La escuela no es una empresa. Barcelona: Paidós.

- (2003). El gran mercado de la educación. En La escuela no es una empresa. Barcelona: Paidós.

MendozA, J. (2004). Revista de la Educación Superior, vol. XXXIII(1), 129, enero-marzo. Recuperado de: https://bit.ly/2R3XUA7. 
Schugurensky, D. y Torres, C. A. (2001). La economía política de la educación superior en la era de la globalización neoliberal: América Latina desde una perspectiva comparatista. Perfiles Educativos, 23(92), tercera época.

Universidad Nacional Autónoma de México (1999). Gaceta UNAM, 3262, 16 de marzo.

VILAS, C. (1998). De ambulancias, bomberos y policías: La política social del neoliberalismo (notas para una perspectiva macro). En Las políticas sociales de México en los años noventa. México: Plaza y Valdés, FLACSO, UNAM. 